\title{
Cleaning-in-place of immunoaffinity resins monitored by in situ ATR-FTIR spectroscopy
}

\author{
Maxime Boulet-Audet ${ }^{1,2} \cdot$ Bernadette Byrne $^{2} \cdot$ Sergei G. Kazarian ${ }^{1}$
}

Received: 10 May 2015 /Revised: 10 June 2015 / Accepted: 18 June 2015 / Published online: 10 July 2015

(C) The Author(s) 2015. This article is published with open access at Springerlink.com

\begin{abstract}
In the next 10 years, the pharmaceutical industry anticipates that revenue from biotherapeutics will overtake those generated from small drug molecules. Despite effectively treating a range of chronic and life-threatening diseases, the high cost of biotherapeutics limits their use. For biotherapeutic monoclonal antibodies (mAbs), an important production cost is the affinity resin used for protein capture. Cleaning-in-place (CIP) protocols aim to optimise the lifespan of the resin by slowing binding capacity decay. Binding assays can determine resin capacity from the mobile phase, but do not reveal the underlying causes of Protein A ligand degradation. The focus needs to be on the stationary phase to examine the effect of CIP on the resin. To directly determine both the local Protein A ligand concentration and conformation on two Protein A resins, we developed a method based on attenuated total reflection (ATR) Fourier transform infrared (FTIR) spectroscopy. ATR-FTIR spectroscopic imaging revealed that applying a carefully controlled load to agarose beads produces an even and reproducible contact with the internal reflection element. This allowed detection and quantification of the binding capacity of the stationary phase. ATR-FTIR spectroscopy also
\end{abstract}

Electronic supplementary material The online version of this article (doi:10.1007/s00216-015-8871-3) contains supplementary material, which is available to authorized users.

Bernadette Byrne

b.byrne@imperial.ac.uk

Sergei G. Kazarian

s.kazarian@imperial.ac.uk

1 Department of Chemical Engineering, Imperial College London, South Kensington Campus, London SW7 2AZ, UK

2 Department of Life Sciences, Imperial College London, South Kensington Campus, London SW7 2AZ, UK showed that Protein A proteolysis does not seem to occur under typical CIP conditions (below $1 \mathrm{M} \mathrm{NaOH}$ ). However, our data revealed that concentrations of $\mathrm{NaOH}$ above $0.1 \mathrm{M}$ cause significant changes in Protein A conformation. The addition of $>0.4 \mathrm{M}$ trehalose during CIP significantly reduced $\mathrm{NaOH}-$ induced ligand unfolding observed for one of the two Protein A resins tested. Such insights could help to optimise CIP protocols in order to extend resin lifetime and reduce $\mathrm{mAb}$ production costs.

Keywords Infrared spectroscopy · ATR FT-IR •

Spectroscopic imaging $\cdot$ Immunoglobulin $\cdot$ Immunoaffinity chromatography $\cdot$ Unfolding

\section{Introduction}

Biotherapeutics were worth over $\$ 165$ billion in $2012[1,2]$ and accounted for $60 \%$ of new drug patents filed by the ten largest pharmaceutical companies [3]. The market share of biotherapeutics is expected to grow to $32 \%$ by 2023 [4]. Thanks to their remarkable specificity [5], many monoclonal antibodies (mAbs) have great potential for the treatment of chronic diseases, cancer and other life-threatening diseases [6]. Extracted from living systems cultured in highly controlled bioreactors, the largest industrial $\mathrm{mAb}$ batch yields are on the kilogramme scale while tonnes of synthetic drugs can be produced in a single batch $[7,8]$. Because of the biological nature of $\mathrm{mAb}$ biotherapeutics, regulatory agencies demand more stringent clinical studies for biotherapeutics than for small molecule drugs due to the potential for adverse immune responses or organ-specific effects [2]. In addition, the requirements for high protein purity and low virus clearance values further increase the production cost. Despite the proven effectiveness of mAbs, the National Institute for 
Health and Clinical Excellence (NICE) often recommends against making them available to patients because of their prohibitive cost. NICE typically rejects mAbs costing more than $£ 20 \mathrm{k}$ per quality-adjusted life year (QALY) while some mAbs can cost more than $£ 116 \mathrm{k}$ per QALY [9]. Off-patent biosimilar mAbs should reduce the treatment price by 20 $40 \%$, but this is a small reduction compared to the $80 \%$ savings made for biosimilars of small molecule drugs.

With improved bioreactor efficiencies for $\mathrm{mAb}$ production, downstream processing now accounts for more than $70 \%$ of total production costs. The immunoaffinity chromatography resin needed for $\mathrm{mAb}$ capture has the biggest impact on production, representing more than $50 \%$ of the cost of goods [8]. Such resin comprises cross-linked agarose beads functionalised with Protein A which binds to the constant fragment crystallisable $(\mathrm{Fc})$ of mAbs [10]. Protein A can be isolated from the native source, the cell wall of Gram-positive Staphylococcus aureus, but can also be expressed recombinantly in Escherichia coli $[11,12]$. Protein A chromatography effectively removes $\sim 98 \%$ of the host cell proteins and other biological impurities from the culture fluid in a single step [13-15]. Unfortunately, Protein A chromatography suffers from a gradual loss of binding capacity over repeated purification cycles [16] as mAb aggregates and biological impurities can bind irreversibly to the column $[16,17]$.

Cleaning-in-place (CIP) protocols typically include washing the resin with alkaline solutions $[18,19,13]$ to prevent contaminant build-up. Sodium hydroxide solutions can efficiently remove precipitated proteins, lipids and nucleic acids while inactivating bacteria, viruses, yeast and endotoxins [20, 21]. High $\mathrm{pH}$ conditions during CIP also inactivate microbes while removing contaminants that could carry over into subsequent purification cycles [22]. However, even with CIP, the $\mathrm{mAb}$ binding capacity of the Protein A resin binding capacity decays over purification runs, typically requiring replacement after 50 to 300 cycles $[16,18]$. Replacing a single industrialscale $1500-\mathrm{L}$ protein A column can cost up to $\$ 12 \mathrm{M}$, not including the incurred production interruptions [8]. Important cost savings could result from optimisation of CIP protocols to extend the resin lifespan.

Previous reports point to ligand degradation during CIP as the primary factor causing binding capacity decay $[23,16]$. A slight change in the protein conformation from alterations in the native tertiary structure contacts can even affect functionality [24]. GE Healthcare bioengineered the Protein A ligand for MabSelect $\mathrm{SuRe}^{\mathrm{TM}}$, offering superior resistance to alkaline conditions. Substituting asparagine and glutamine residues greatly reduces protein sensitivity to deamidation, the removal of amide functions, at high $\mathrm{pH}$ [25]. Optimised CIP protocols using salt and excipients can help prevent ligand degradation during CIP [12].

Static and dynamic binding assays can quantify the binding capacity $[17,16,26]$, but such analyses only provide information on the loss of function. Enzyme-linked immunosorbent assay (ELISA) can also be used to measure traces of Protein A ligand leaching from columns [13]; however, the amount of ligand lost cannot fully explain the loss of binding capacity. Without methods to reveal the underlying cause of Protein A ligand decay, efforts to optimise CIP protocols remain limited [17]. This study aimed to identify the main cause of Protein A ligand degradation and loss of binding capacity through direct analysis of the immobilised Protein A ligand.

By measuring the resin directly, attenuated total reflection (ATR) FTIR spectroscopy is particularly well suited to identify the cause of ligand degradation. Unlike other techniques such as circular dichroism, dynamic light scattering or mass spectrometry, FTIR spectroscopy and FTIR spectroscopic imaging can easily probe heterogeneous samples such as agarose beads. Previous studies have used thick transmission cells to study agarose beads in single layers [27]. However, the attenuated total reflection (ATR) mode avoids the issue of buffer from masking the protein's spectral regions of interest. Because ATR mode probes only a thin layer of the sample adjacent to the surface, ATR-FTIR spectroscopy is much more sensitive to bound ligand than transmission mode. Infrared spectroscopy provides information on protein conformation $[5,28-33]$ and can thus determine the effect of CIP on the structure of the immobilised ligand.

We developed a highly reproducible ATR-FTIR spectroscopy method to probe agarose resin directly. Because the ATR mode requires an intimate contact between the sample and the internal reflection element, we applied pressure to the resin beads rather than decreasing their size [34], using polymer binders [35], or substituting the matrix for a flat surface $[36,37]$. The absorbance measured from convex partials depends on the load applied [38]. Since a typical ATR accessory cannot control the load precisely enough for reproducible measurements, we mounted a load sensor to measure the force applied to the resin. This approach yielded highly reproducible spectra, revealing the Protein A density and conformation from only a few hundred resin beads without the need for extensive sample preparation [39].

After quantifying the static binding capacity from the mobile phase using $280 \mathrm{~nm}$ absorption, we analysed the stationary phase by ATR-FTIR spectroscopy. Resin samples were measured following a range of CIP conditions as well as during $\mathrm{NaOH}$ incubation in situ. This approach revealed the cause of binding capacity decay by determining the amount of adsorbed protein on the beads and the conformation of the immobilised protein ligand. Our results indicate the minimum $\mathrm{NaOH}$ concentration inducing ligand unfolding. A disaccharide was also found to reduce the impact of alkaline conditions. This approach and derived insights should help direct optimisation of CIP protocols to preserve the resin's binding capacity. 


\section{Materials and methods}

\section{Monoclonal antibody preparation}

The monoclonal antibody ( $\mathrm{mAb}$ ) expression and purification is described in detail elsewhere [31]. Glutamine Synthetase Chinese Hamster Ovary (GS-CHO) cell lines that express the chimeric B72.3 immunoglobulin G gamma 4 (IgG4) were provided by Lonza (Lonza Biologics, Basel, Switzerland). The mAb concentration in the different media samples was quantified by ELISA (Montgomery, TX, US) and UV-vis spectroscopy using a Nanodrop Lite system (Thermo, Wilmington, DE, USA). The media containing the protein was then desalted using a HiPrep 26/10 desalting column (GE Healthcare Life Sciences) equilibrated with Buffer A (20 mM phosphate, $\mathrm{pH}$ 7.4). Subsequently, the IgG4 mAbs were captured using protein A chromatography with Recombinant Protein A Sepharose ${ }^{\circledR}$ FF resin (Generon Ltd, UK). The protein was further purified by anion exchange chromatography using a HiTrap Q FF prepacked with Q Sepharose (GE Healthcare Life Sciences). The purified protein was then concentrated by centrifugal filtration using a molecular weight cut-off of $50 \mathrm{kDa}$ to $4 \mathrm{mg} / \mathrm{mL}$ for the stock solution.

\section{Resin preparation and static binding capacity assays}

Pierce Control Agarose Resin (Thermo Scientific, USA), Recombinant Protein A Sepharose ${ }^{\circledR}$ FF resin (Generon Ltd, UK) and MabSelect ${ }^{\mathrm{TM}} \mathrm{SuRe}^{\mathrm{TM}}$ Protein A resin (GE Life Sciences, UK) are constituted of porous cross-linked agarose beads ranging from 20 to $160 \mu \mathrm{m}$ in diameter. For in situ measurements, resin samples were mixed with a $\mathrm{NaOH}$ solution to achieve a $420 \mathrm{mM}$ final concentration just before ATR-FTIR spectroscopic kinetic measurements.

To increase throughput and test multiple CIP conditions, ATR-FTIR spectroscopic measurements were performed after the incubation (ex situ) following the flow chart in Fig. 1. Protein A Sepharose, MabSelect SuRe and $10 \mu \mathrm{L}$ of sedimented resin were transferred into 1-mL micro spin columns (Bio-Rad, USA). To test the effect of alkalinity, resin samples were subsequently incubated for $10 \mathrm{~h}$ with the cleaning-in-place solution containing $\mathrm{NaOH}$ at concentrations ranging from 0 to $6450 \mathrm{mM}$. To enhance diffusion, samples were stirred gently on a roller during incubation. Protein A resin is typically sanitised with $3 \mathrm{CV}$ of $\mathrm{NaOH}$ at 0.1 to $1 \mathrm{M}$, with a 30-min contact time [16], corresponding to 20 sanitation cycles. To test the effect of D-(+)-trehalose (Sigma Aldrich, USA) on Protein A ligand during CIP, a series of resin samples were incubated for $16 \mathrm{~h}$ in $215 \mathrm{mM} \mathrm{NaOH}$ mixed with disaccharide at concentrations ranging from 0 to $700 \mathrm{mM}$. Following CIP, resin samples were washed three times with $20 \mathrm{mM}$ phosphate buffer at $\mathrm{pH} 7.4$ by spinning the column. A mAb stock solution was then added to obtain a final concentration of $4.55 \mathrm{mg} / \mathrm{mL}$ in $0.2 \mathrm{~mL}$ of binding

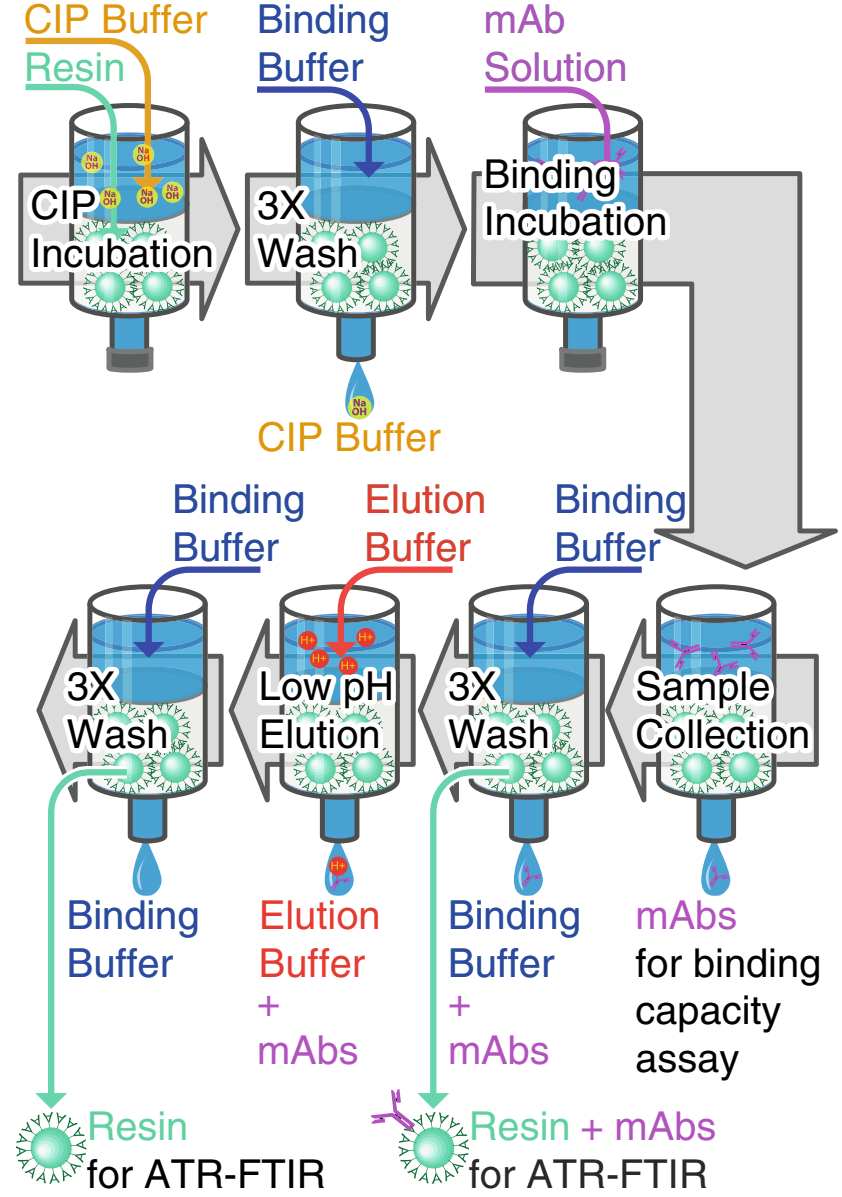

Fig. 1 Flow chart depicting the method for the preparation of the resin samples

buffer. After a 3-h contact time, the concentration of mAbs left in solution was measured using UV at $280 \mathrm{~nm}$ with $E^{1 \%}=$ 13.7. The static binding capacity $q$ was calculated from the difference in protein concentration measured. To remove unbound mAbs, samples were subsequently washed with binding buffer three times. Aliquots of resin with bound mAbs were then collected to determine the binding capacity by probing the stationary phase with ATR-FTIR spectroscopy. To release and elute the $\mathrm{mAbs}$ from the resin, samples were subsequently washed with $20 \mathrm{mM}$ phosphate buffer $\mathrm{pH}$ 3.0. The $\mathrm{mAb}$-free resin samples were washed again with binding buffer three times before performing another series of ATRFTIR spectroscopic measurements.

\section{ATR-FTIR experimental set-up}

The sample cell shown in Fig. 2 was made from Sylgard ${ }^{\circledR} 184$ PDMS (Dow Corning Corporation, USA) cast from an acrylic 3D printed mould (Shapeways, New York, USA). This was attached to a Golden Gate (Specac, UK) diamond attenuated total reflection accessory to probe the bottom of the cell. Two microlitres of sedimented resin beads were first loaded into the 


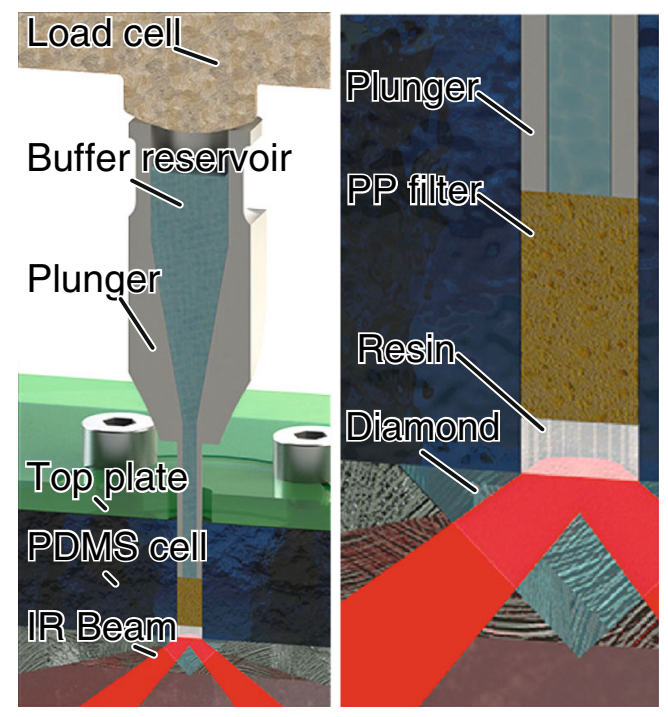

Fig. 2 Schematic presentation of the experimental setup used for resin analysis by ATR-FTIR spectroscopy and spectroscopic imaging. The polydimethylsiloxane (PDMS) cell was clamped to the ATR accessory using an acrylic top plate while a plunger applied the load on the resin beads. The force applied was measured by a load cell mounted on top of the plunger

1.3-mm well and gravity packed onto the diamond internal reflection element (IRE) before collecting the buffer background spectrum. To obtain a good contact between the beads and the IRE, a stainless steel plunger pressed the resin with a porous polypropylene (PP) filter. The excess buffer flowed through the PP into the plunger's buffer reservoir. The PP filter distributed the load evenly while allowing the flow of buffer to prevent trapping air in the well. An iLoad Mini load cell (Loadstar Sensors, USA) monitored compression force as the plunger was lowered down the well at $\sim 0.5 \mathrm{~mm} / \mathrm{min}$. Once the filter touched the resin beads, the force reading rose rapidly by around $30 \%$ as the PP filter deformed under load. Unless specified otherwise, target load after relaxation was $200 \mathrm{~g}$ (1.5 MPa). Typical compression curves with and without resin are shown in Electronic Supplementary Material (ESM) Fig. S1. Under load, the beads flatten sufficiently to be probed effectively by the evanescent wave.

After collecting spectra, the entire PDMS cell was unclamped to clean the IRE and the PDMS cell. Recovered beads appeared unaffected by the gentle load as shown in ESM Fig. S2. The sample loading, cell cleaning, spectrum and background collection took less than 6 min per aliquot with five aliquots measured for each condition tested.

The concentration of isolated Protein A from S. aureus standard solution series was determined by UV absorption at $280 \mathrm{~nm}$ with a Nano drop Lite (Thermo, USA) using $E^{1 \%}=$ 1.65 [10]. The absorbance of the amide II was integrated to quantify the protein A concentration using the calibration curve (ESM Fig. S3).

\section{ATR-FTIR spectroscopy}

Attenuated total reflection (ATR) Fourier transform infrared (FTIR) spectra were collected using a Varian 670 spectrometer (Agilent Technologies, UK) equipped with a Peltier-cooled deuterium tri-glycine sulphate (DTGS), single-element pyroelectric detector. Hydrated beads in buffer were probed by ATR mode using a reflection diamond Golden Gate accessory with optics suitable for spectroscopic imaging (Specac, UK) [40]. The $45^{\circ}$ angle of incidence resulted in the depth of penetration of $\sim 1.2 \mu \mathrm{m}$ at $1600 \mathrm{~cm}^{-1}$ on the diamond's surface [40, 41]. ATR-FTIR spectra were collected at a $4-\mathrm{cm}^{-1}$ resolution using an aperture equivalent to a resolution of $0.5 \mathrm{~cm}^{-1}$. For ex situ measurements after incubation, 64 scans were co-averaged while 128 scans were collected for each time frame in situ experiments during incubation.

For ATR-FTIR spectroscopy using a single-element DTGS detector, infrared spectra were collected using Resolution Pro 5.2 (Agilent Technologies Ltd, USA) before being imported into MATLAB. We estimated that the optimal subtraction coefficient for the buffer was around 0.95 based on the subtraction of the combination band (libration $+\mathrm{OH}$ bending) at $2125 \mathrm{~cm}^{-1}$ [42]. Despite a $\sim 5 \%$ water buffer over subtraction, we fixed the subtraction coefficient to 1 to improve the measurement reproducibility. The dependence of the depth of penetration on the wavelength was also corrected [43].

\section{ATR-FTIR spectroscopic imaging}

For ATR-FTIR spectroscopic imaging, the diamond ATR accessory was placed in an external large sample compartment and data collected using a cooled mercurycadmium-telluride (MCT) focal plane array (FPA) displaying 128 by 128 elements capable of collecting 16384 spectra simultaneously [32]. Since about a quarter of the FPA was illuminated by the optics, the size of the images was set to 64 by 64 (4096 spectra). The imaging spectra were also collected at $4 \mathrm{~cm}^{-1}$ and 64 scans were co-averaged for each image. The focusing lenses of the imaging IR accessory corrected partially for the beam aspect ratio distortion, resulting in a near square field of view of $\sim 0.64$ by $\sim 0.52 \mathrm{~mm}$ [32].

Interferograms were collected using Resolution Pro 5.2 and saved as binary files. All subsequent data analysis operations were performed by a MATLAB (MathWorks, Natick, MA, USA) custom code as described elsewhere [31]. The algorithm applied an offset using the 1900 to $1850 \mathrm{~cm}^{-1}$ window before correcting for the penetration depth variation depending on the wavelength of light [43]. 


\section{Results and discussion}

\section{Effect of load on resin by ATR-FTIR spectroscopic imaging}

To better understand the causes of binding capacity decay, the Protein A resin needs to be probed directly. ATR-FTIR spectroscopy is well suited for probing solid materials while being sensitive to protein conformation [28, 29]. However, the ATR evanescent wave only probes a thin sample layer in close contact with the IRE as shown in Fig. 2. Measuring chromatography resins by ATR-FTIR spectroscopy thus poses a challenge as they typically consist of convex 30 to $150 \mu \mathrm{m}$ porous agarose microspheres. Compared to a thick liquid film, an area covered by $4-\mu \mathrm{m}$ beads would absorb infrared light five times less while $50-\mu \mathrm{m}$ beads would result in only $2 \%$ of the potential absorbance [38]. Reducing bead size would thus increase sensitivity [34], but would not represent the industry's standard chromatographic media. Instead, we opted for squeezing beads onto the internal reflection element in order to increase contact [38].

With a Young's modulus of only 100 to $200 \mathrm{kPa}$ [44], the contact of soft agarose beads with the IRE should depend on the load [38]. Mounted on the plunger (Fig. 2), a load cell accurately measured the force on the resin beads $( \pm 30 \mathrm{mN})$. After lowering the plunger, the stress reduces as the filter relaxes (ESM Fig. S1). To visualise the contact between the resin beads and the IRE, a focal plane array (FPA) detector collected ATR-FTIR spectroscopic images of the resin beads under load.

Figure 3 shows that the contact between the beads and the IRE varies with the applied load. Integrating absorbance of the main polysaccharide band $\left(1200-1000 \mathrm{~cm}^{-1}\right)$ generated spectroscopic images of the agarose resin beads. A load below $150 \mathrm{~g}$ did not overcome the friction between the PP filter and the PDMS well, resulting in blank images. Over $200 \mathrm{~g}$, the PP filter moved to the bottom of the well and pressed the resin beads against the internal reflection element, resulting in substantial absorption of the evanescent wave. The histogram of the image at $200 \mathrm{~g}$ corresponds to a symmetrical and relatively narrow absorbance distribution, centred around 0.045 absorbance units. Under heavier load, resin beads deform further leading to a distribution maximum shifting towards higher absorbance values as contact improves. Simultaneously, the absorbance distribution widened as a result of more heterogeneous images. Upon high pressure, the apparent diameter of squashed microspheres can become even greater than their uncompressed diameter [38]. Despite weaker absorbance, we choose to apply the minimum load required to obtain a sufficient and reproducible contact $(200 \mathrm{~g}$ or 1.5 MPa). The resin polysaccharide absorbance vanished after removing the load as beads relaxed to their original spherical shape. Unlike other studies that relied on spectra collected

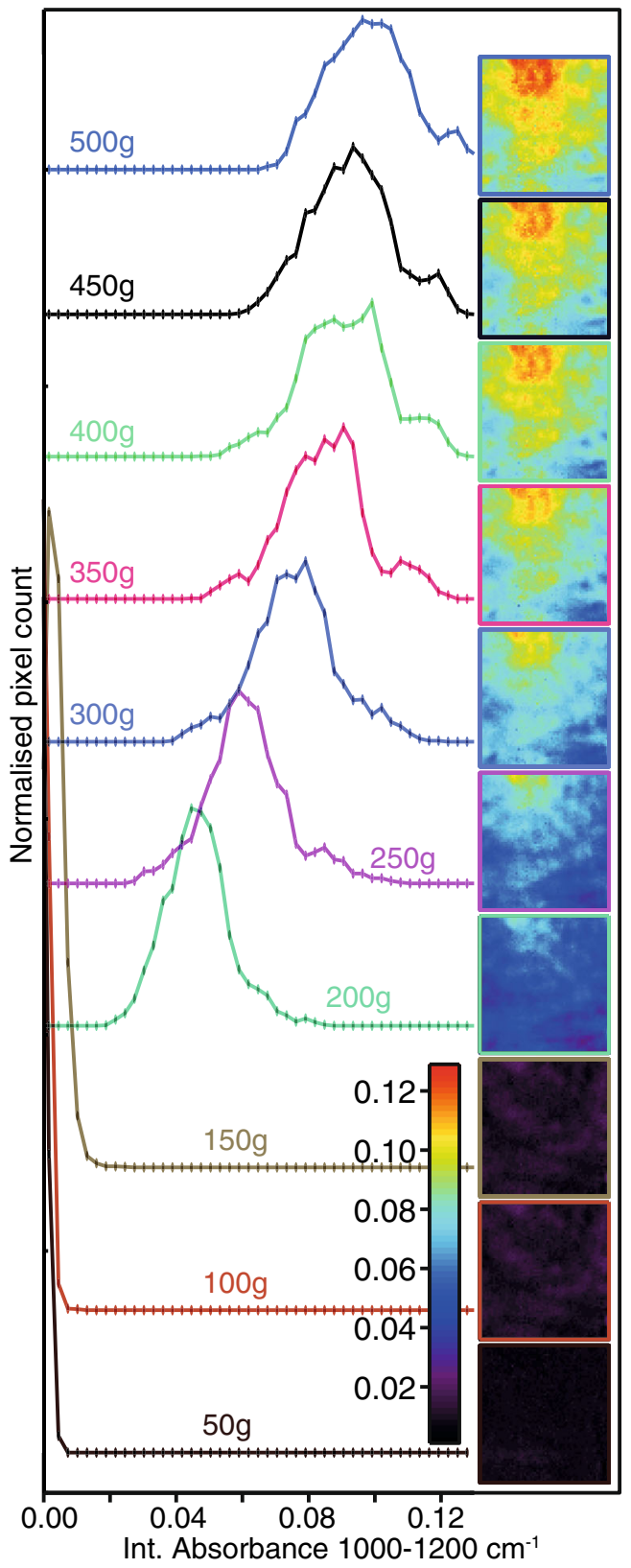

Fig. 3 ATR-FTIR spectroscopic images (right) based on the distribution of integrated absorbance in the 1200 to $1000 \mathrm{~cm}^{-1}$ region for Protein A Sepharose resin under a 50- to 500-g load. The corresponding histograms (left) show the pixel count rate as a function of the integrated absorbance. The images' field of view was $\sim 0.64 \times 0.52 \mathrm{~mm}$ [32]

from dried and crushed resin [39], this approach does not appear to damage agarose beads (ESM Fig. S2).

Multiple load cells to ensure reproducible contact could be used in combination with FTIR spectroscopic imaging to allow high-throughput measurements $[31,32,45]$. FTIR spectroscopic imaging could also prove particularly powerful to investigate the distribution of impurities building up in flowing systems. Since beads cover the field of view evenly under a 200-g load, FTIR spectroscopic experiments may also be conducted using conventional single-element detectors. 
Measuring agarose beads with conventional FTIR spectroscopy could thus become a routine method to support protocol validation.

\section{ATR-FTIR spectra of resin}

Since infrared spectra are indicative of the particular chemical composition, we used our resin probing platform to compare three types of hydrated chromatographic resins. This method produced a high signal-to-noise ratio and reproducible ATRFTIR spectra from only a few hundred beads and in less than 6 min per aliquot.

Figure 4 shows clear differences between bare agarose, rProtein A Sepharose and MabSelect resins. The brown spectrum of bare agarose shows strong bands at $1064 \mathrm{~cm}^{-1}$ due to $\mathrm{C}-\mathrm{O}$ stretching/C-O- $\mathrm{H}$ bending from hydroxyl functions and at 1378,1186 and $1149 \mathrm{~cm}^{-1}$ from polysaccharide skeletal modes [46, 47]. No bands appear between 1500 and $1700 \mathrm{~cm}^{-1}$, but the slightly negative absorbance results from over-subtracting the absorbance of the band corresponding to the bending mode of water at $1638 \mathrm{~cm}^{-1}$ from the displaced buffer [48]. The spectrum of agarose functionalised with Protein A (Sepharose, teal curve) presents strong protein bands. As a reference, the grey trace in Fig. 4 shows the infrared absorption of Protein A with the expected amide bands peaking at 1653,1546 and $1251 \mathrm{~cm}^{-1}$. The maximum amide I absorption at $1653 \mathrm{~cm}^{-1}$ indicates a predominantly helical

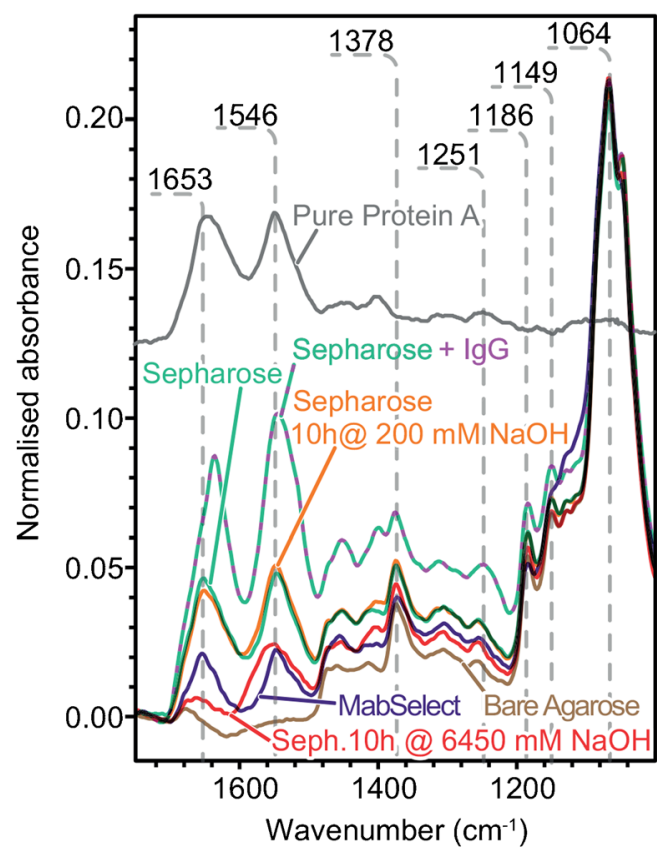

Fig. 4 ATR-FTIR spectra of untreated agarose resin (brown) under a 200-g load, MabSelect Sure resin (blue), Sepharose resin (teal), Sepharose resin with bound mAbs (teal with fuchsia dashes), Sepharose resin treated for $10 \mathrm{~h}$ with $200 \mathrm{mM} \mathrm{NaOH}$ (orange) and $6450 \mathrm{NaOH}$ (red). The ATR-FTIR spectrum of pure Protein A in solution (grey) is offset to improve visualisation conformation $[28,29]$, in agreement with the known crystalline structure [49]. Polysaccharide peaks overlap protein side chain vibration modes between 1500 and $1300 \mathrm{~cm}^{-1}$ and the amide III band [30], but, fortunately, do not interfere with the amide I and II bands above $1500 \mathrm{~cm}^{-1}$. Presented as an indigo curve, the infrared spectrum of MabSelect resin shows some slight differences in the polysaccharide region around $1149 \mathrm{~cm}^{-1}$ compared to the rProtein A Sepharose resin. The difference might arise from the higher degree of cross-linking for MabSelect matrix [12]. However, MabSelect has substantially weaker amide I and II bands, implying a lower Protein A ligand density. Using this method, we could thus probe immobilised Protein A ligand directly on agarose beads using ATR-FTIR spectroscopy for the first time.

\section{Protein A ligand density quantification}

ATR-FTIR spectroscopy represents a convenient and nondestructive method to quantify Protein A ligand density on resin beads. Ligand density is typically estimated roughly by UV absorption difference in the buffer. Alternatively, concentration can be measured in transmission mode through thin resin samples after adjusting the refractive index, which is not very practical [14]. Elemental or amino acid analysis represents another alternative by accurately quantifying ligand density, but such techniques require matrix digestion [50]. In transmission mode, infrared absorption would saturate in the amide I and II regions when using a beam path thicker than $10 \mu \mathrm{m}$, considerably thinner than the smaller agarose beads studies $(>50 \mu \mathrm{m})$. Because the evanescent wave probes around $1 \mu \mathrm{m}$ deep into samples when using a diamond with a $45^{\circ}$ angle of incidence [41, 43], spectra collected in ATR mode do not saturate in the mid-infrared region.

Since the absorbance of the amide bands is proportional to the protein concentration, infrared spectra can thus be used to determine the amount of bound Protein A ligand. Using a protein A calibration curve, we calculated a local concentration of $84 \pm 9 \mathrm{mg} / \mathrm{mL}$ for rProtein A Sepharose, more than twice the amount on MabSelect $(31 \pm 9 \mathrm{mg} / \mathrm{mL})$. We expected a difference since manufacturers reported a Protein A ligand density of 3.5 and $1.64 \mathrm{mg} / \mathrm{mL}$ for Sepharose and MabSelect, respectively [12]. Nevertheless, comparable binding capacities were still reported for MabSelect [16, 12]. The shallow penetration depth of the proving wave explains the proportionally high protein absorbance measured relative to the protein to dry polysaccharide ratio $(\sim 12 \%=3.5 / 29 \mathrm{mg})$. ATR is thus more sensitive to bound Protein A ligands on the surface than in the agarose matrix [14]. Compared to transmission, ATR mode is thus a more sensitive method for the quantification of the Protein A ligands. ATR spectra are indicative of the local protein density in a layer adjacent to the surface of internal reflection element rather than of the total amount of 
Protein A ligand. The local concentration should still be proportional to the total density when assuming an even coverage.

\section{In situ cleaning-in-place}

The ligand must be measured directly rather than indirectly through reduced binding capacity to identify the cause of binding capacity. Because binding capacity loss occurs without product following CIP, alkaline conditions appear to be mainly responsible for Protein A ligand degradation [16, 12, 26]. Under chemical stress such as high $\mathrm{pH}$, proteins will eventually denature as a result of proteolysis, deamidation or unfolding. Proteolysis can cause loss of the entire protein ligand or protein fragments from the resin, decreasing ligand density. Under denaturing conditions, the mobility of the backbone increases which in turn allows the protein conformation to change [51]. Deamidation also occurs faster at high $\mathrm{pH}$ causing the asparagine residues to react with the backbone, resulting in side chain alterations and changes in protein conformation. Because binding capacity cannot discriminate between these effects, the ligand must be analysed directly instead.

Indicative of the Protein A conformation, ATR-FTIR spectroscopy revealed that protein unfolding is the likely cause of Protein A ligand denaturation $(<1 \mathrm{M} \mathrm{NaOH})$. Proteolysis, unfolding and deamidation are detectable in the amide band regions [30, 31, 52-54]. The orange spectrum of Fig. 4 shows that exposure to $200 \mathrm{mM} \mathrm{NaOH}$ for $10 \mathrm{~h}$ affects mainly the amide I and II band positions. Such a band shift can be indicative of conformational change. Since the amide band absorbance remained constant after CIP and the wash step, our result implies that proteolysis is not an important contributor to ligand degradation. In addition, no $\mathrm{COOH}$ peak appeared between 1710 and $1760 \mathrm{~cm}^{-1}$ [30], suggesting that few Asn side chains underwent deamidation. Based on infrared spectra, Protein A unfolding is thus the most likely cause of ligand denaturation under typical CIP alkaline conditions.

Since the amide II band responds more to conformation changes than the amide I [53, 29], we calculated the centre of gravity (COG) of the $1575-1525 \mathrm{~cm}^{-1}$ amide II region precisely to detect the effect of $\mathrm{NaOH}$ on the protein ligand. The COG does not depend on the absolute absorbance and can detect band shifts smaller than the spectral resolution $[52,55]$. In a sealed system, we incubated Protein A resin samples under typical $\mathrm{NaOH}$ concentrations used for CIP while collecting infrared spectra to calculate the amide II COG.

Figure 5 shows that ATR-FTIR spectroscopy can detect subtle Protein A ligand conformation changes during CIP in situ. For both rProtein A Sepharose and MabSelect resin exposed to $420 \mathrm{mM} \mathrm{NaOH}$, the amide II COG shifted to a higher wavenumber as a function of time. The COG shifted faster at the beginning of the incubation than after $\sim 4 \mathrm{~h}$, particularly for

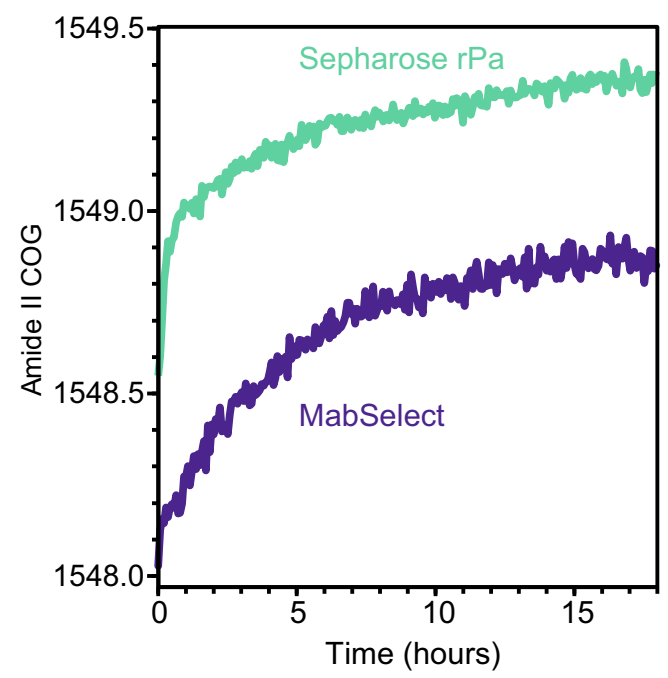

Fig. 5 Amide II band centre of gravity (COG) as a function of time for a typical rProtein A Sepharose resin and MabSelect resin under $420 \mathrm{mM}$ $\mathrm{NaOH}$ CIP. See ESM Fig. S4 for a close-up of the amide I and II region for different samples under a 200 -g load

the Sepharose resin. The amide II band still continued to rise, albeit slowly, after exposing the resin to $\mathrm{NaOH}$ for $18 \mathrm{~h}$ suggesting that unfolding is not complete even after prolonged exposure times. Under such CIP conditions, the resin would be expected to have lost substantial binding capacity and be rendered unusable [16]. ATR-FTIR spectroscopy could thus follow the ligand's structure during CIP steps without the need to interfere with the production pipeline or rely on $\mathrm{mAb}$ binding interactions.

The varying rate of amide II COG shift could be attributable to buffer diffusion as the thin layer near the bead surface was exposed to $\mathrm{NaOH}$ first before it could have diffused through the matrix. According to this hypothesis, less frequent but longer exposure periods could be less detrimental to the ligand protein conformation while being equally effective at CIP. To validate such a hypothesis, a subsequent study would be needed, where the buffer conditions are changed sequentially.

\section{Effect of $\mathrm{NaOH}$ concentration on the binding capacity and resin ligand}

In addition to the exposure time, the concentration of $\mathrm{NaOH}$ was also identified as an important parameter for CIP protocols [16]. Because only one sample could be measured in situ, testing different conditions would be very time consuming. Instead, we incubated several individual resin samples under a range of $\mathrm{NaOH}$ concentrations simultaneously, then washed them with binding buffer prior to static binding capacity assays using stock mAb solution. Subsequently, half of the resin aliquots were washed with low $\mathrm{pH}$ elution buffer to release the mAbs. Resin samples with and without bound mAbs were then analysed by ATR-FTIR spectroscopy to quantify the 
adsorbed protein density using the amide II integrated absorbance against a calibration curve (ESM Fig. S3). With this approach, many resin aliquots could thus be studied rapidly to test a wide range of buffer compositions.

As previously reported [16], $\mathrm{NaOH}$ can substantially reduce the static binding capacity $(q)$ of protein A resin, although less for the more alkaline resistant MabSelect SuRe. Figure 6a shows the decrease in $q$ of Sepharose and MabSelect SuRe resin as a function of the $\mathrm{NaOH}$ concentration for a contact time of $10 \mathrm{~h}$, equivalent to $20 \mathrm{CIP}$ cycles. For the same amount of protein A resin, MabSelect appears to have a greater $q$ than Sepharose at $0 \mathrm{mM} \mathrm{NaOH}$. For both types of resin, the binding capacity decreased slowly with increasing $\mathrm{NaOH}$ concentration. CIP with more than $800 \mathrm{mM} \mathrm{NaOH}$ severely decreases the binding capacity for both types of resin. At

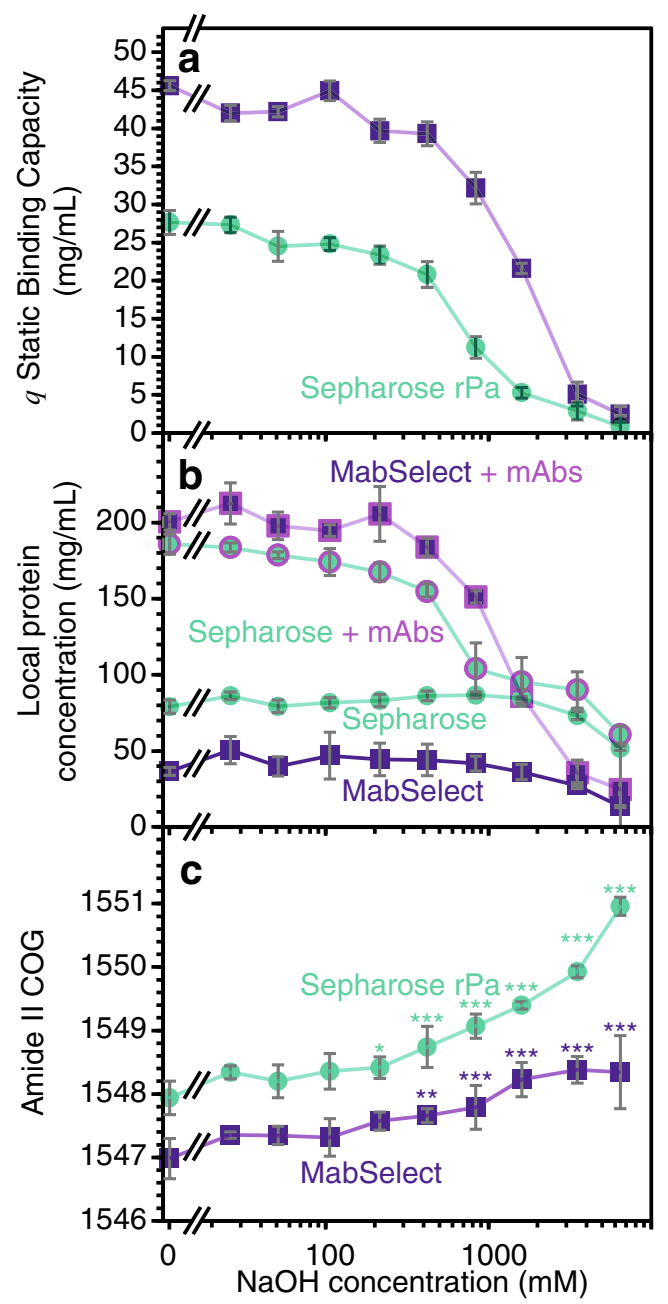

Fig. 6 a Static binding capacity measured from the mobile phase. b Local protein concentration calculated from resin ATR-FTIR spectra of resin with mAbs (fuchsia marker outline) and without bound mAbs (no contour). c Amide II centre of gravity (COG) measurements for rProtein A Sepharose resin (teal) and MabSelect SuRe resin (indigo) following a 10 -h incubation with a range of $\mathrm{NaOH}$ concentrations after low $\mathrm{pH}$ elution. The error bars represent the standard deviation; $* p<0.05$, ${ }^{* *} p<0.01$, and $* * * p<0.001$ as assessed by one-way ANOVA
$1600 \mathrm{mM} \mathrm{NaOH}$, however, MabSelect SuRe preserved half of its binding capacity while Sepharose nearly did not bind any mAbs. At even higher $\mathrm{NaOH}$ concentration, both resins lost almost all binding capacity. To determine the underlying cause of binding capacity loss, resin samples with and without bound mAbs were analysed directly by ATR-FTIR spectroscopy.

Proteolysis occurs at high $\mathrm{NaOH}$ concentrations for both types of resin, but not significantly under typical CIP conditions. The drop in amide band absorption indicated by the red trace in Fig. 4 shows that incubating rProtein A Sepharose with $6450 \mathrm{mM} \mathrm{NaOH}$ causes ligand proteolysis. Figure $6 \mathrm{~b}$ shows the local protein concentration calculated from the bead spectra incubated under a range of $\mathrm{NaOH}$ conditions and washed with elution buffer to unbind mAbs. Compared to the control, only the $6450 \mathrm{mM} \mathrm{NaOH}$ concentration measured caused a significant drop in Protein A concentration for both rProtein A Sepharose and MabSelect. Since typical CIP protocols do not expose the resin to such harsh conditions [19, 16], this result confirms that binding capacity decay does not arise from proteolysis. Hence, measuring Protein A ligand leaching by ELISA [13] is unlikely to be indicative of binding capacity decay reasserting the need for direct resin measurements.

The amount of adsorbed protein detected by ATR-FTIR spectroscopy also depends on the CIP conditions and the type of resin. When incubating the protein A resin with mAbs, the absorbance of the amide bands increase due to the adsorbed protein (teal with fuchsia dashes, Fig. 4). Figure $6 \mathrm{~b}$ shows the difference between the local protein concentration between resin washed with elution buffer (Protein A only) and washed with binding buffer (Protein $\mathrm{A}+\mathrm{mAbs}$, fuchsia marker outline). This difference vanishes above $1600 \mathrm{mM} \mathrm{NaOH}$ concentration as a non-significant amount of mAbs is adsorbed to the resin beads. Once again, MabSelect SuRe appears to better preserve binding capacity at $800 \mathrm{mM} \mathrm{NaOH}$ with a significant difference of protein adsorbed compared to the sample without bound mAbs.

Without bound $\mathrm{mAbs}, \mathrm{NaOH}$ affects the protein conformation of the protein A ligand under typical CIP conditions, particularly for the less resistant rProtein A Sepharose. From the same spectra set, Fig. $6 \mathrm{c}$ shows the amide II COG of the resin aliquots washed with elution buffer. Different ligand density could explain the difference in COG between Sepharose and MabSelect at $0 \mathrm{mM} \mathrm{NaOH}$. The lower Protein A ligand density on MabSelect SuRe caused larger measurement standard deviations. For both resin types studied, a definite trend arises as the amide II COG shifted toward higher wavenumbers with increasing $\mathrm{NaOH}$ concentration. Treatment with only $200 \mathrm{mM} \mathrm{NaOH}$ resulted in a significant amide II band COG shift for rProtein A Sepharose while a significant change for MabSelect was only observed at concentrations of $\mathrm{NaOH}$ above $400 \mathrm{mM}$. The superior resistance of MabSelect 
becomes even more apparent at high concentration with the Amide II band of Sepharose resin shifting much more at $3510 \mathrm{mM} \mathrm{NaOH}$. Engineered to improve high $\mathrm{pH}$ stability by replacing asparagine residues $[12,56,16]$, the greater stability of MabSelect was expected. Despite the larger statistical errors, our results suggest that MabSelect is indeed more resistant to protein unfolding under typical conditions used for CIP.

The local protein concentration on the beads, measured by ATR-FTIR spectroscopy, relates to the static binding capacity (q) measured by $280 \mathrm{~nm}$. Subtracting the local protein concentration of the resin without $\mathrm{mAbs}$ removes the contribution of the adsorbed Protein A ligand. Figure 7 a shows the difference in adsorbed protein concentration as a function of $q$. The amount of adsorbed mAbs detected by ATR-FTIR varies linearly with the concentration of mAbs measured in the mobile phase $\left(R^{2}=0.94\right.$ for Sepharose and $R^{2}=0.96$ for MabSelect). As expected, the same linear trend was observed for both types of resin since the same mAb was used. We concluded that measuring the stationary phase by ATR-FTIR to quantify the ligand density could thus present an alternative to UV $280 \mathrm{~nm}$ for the quantification of the static binding capacity. Under milder conditions, more subtle conformation changes such as altered tertiary contacts can still affect binding functionality in the absence of proteolysis. With a high degree of interplay expected between tertiary and secondary structural changes [24], we evaluated the potential of infrared spectra as a proxy for binding capacity.

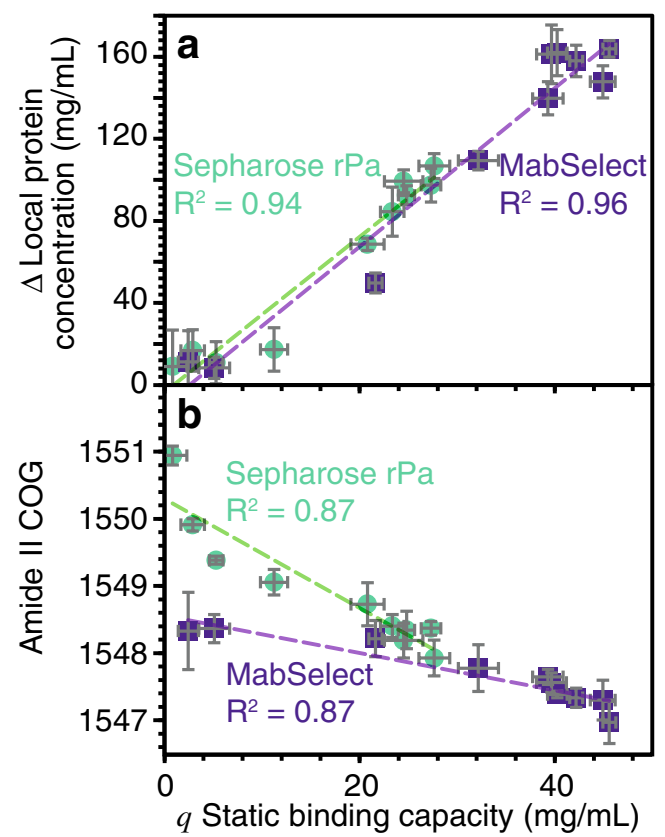

Fig. 7 a Difference in local protein concentration measured by ATRFTIR spectroscopy as a function of the static binding capacity $(q)$. b Amide II band centre of gravity (COG) as a function of the static binding capacity

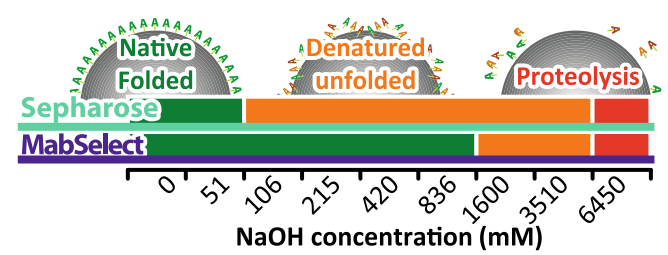

Fig. 8 Schematic illustrating the range of $\mathrm{NaOH}$ concentrations that induced unfolding and proteolysis for the Sepharose and MabSelect resins

The Protein A ligand amide II band measured by ATRFTIR spectroscopy without bound mAbs also appears to relate to $q$. Figure $7 \mathrm{~b}$ shows the amide II band COG as a function of $q$ for both Sepharose and MabSelect SuRe. For both types of resin, the conformation-dependent amide II COG correlates with $q\left(R^{2}=0.87\right.$ for Sepharose and MabSelect). The higher ligand density of Sepharose could explain the steeper negative trend compared to MabSelect as more protein could unfold. Hence, this result suggests that the protein conformation change could relate to the decay of the binding capacity. The amide II COG has the benefit of allowing in situ measurements without relying on $\mathrm{mAb}$ binding interactions.

The schematic in Fig. 8 illustrates the distinction between denaturation caused by proteolysis (red) and through protein unfolding (orange). Our results suggest that only unfolding occurs at $\mathrm{NaOH}$ concentrations typically used for CIP $(<1000 \mathrm{mM})$. Avoiding or reducing conditions causing ligand unfolding should thus help preserve binding capacity and extend resin lifespan. Since the resin binding capacity decays

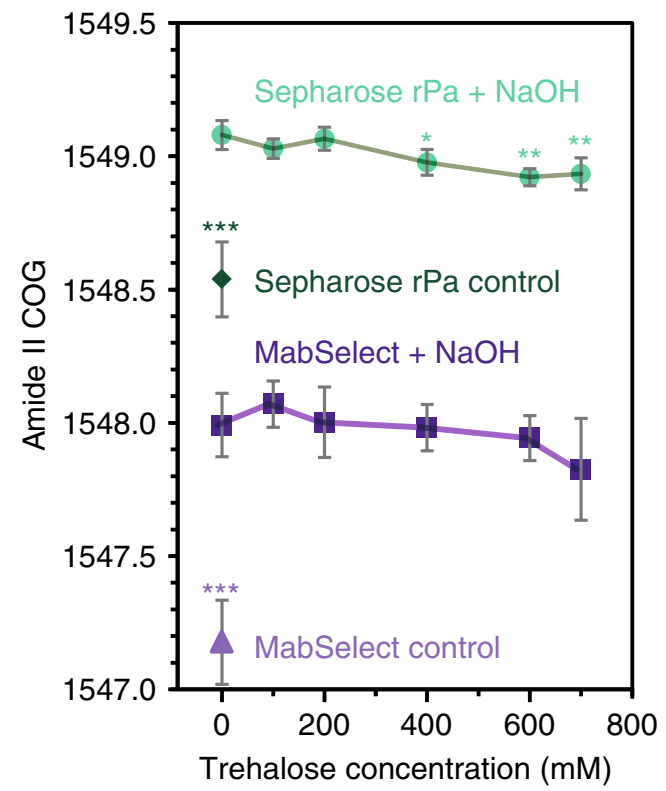

Fig. 9 Amide II band centre of gravity (COG) as a function of $\mathrm{NaOH}$ and trehalose concentration for Sepharose (teal) and MabSelect (indigo) after a 16-h incubation period. The error bars represent the standard deviation; ${ }^{*} p<0.05$ and ${ }^{* *} p<0.01$ as assessed by one-way ANOVA 
over repeated CIP cycles, the exposure time to $\mathrm{NaOH}$ should directly relate to ligand degradation. Since substantial binding capacity loss occurs under such conditions, we hypothesised that ATR-FTIR spectroscopy could provide information on resin binding capacity. To monitor ligand degradation in situ, such ATR-FTIR spectroscopic study of resins should represent an alternative to static and dynamic binding assays requiring mAbs.

\section{Effect of trehalose with $\mathrm{NaOH}$ on the resin}

In addition to reducing $\mathrm{NaOH}$ concentration and exposure time, xylitol, ethylene glycol and $\mathrm{NaCl}$ have previously been found to help preserve resin binding capacity [16]. It is possible that such excipients would offer some degree of protection from denaturation. Some saccharides are known to be able to protect bound water and form hydrogen bonds, which help preserve protein conformation [57-60]. Since trehalose is known to stabilise proteins [61, 62], we investigated the effect of $\mathrm{NaOH}$ on the two resin types in the presence of a range of disaccharide concentrations.

Figure 9 shows a clear difference between the amide II COG for the control samples and those incubated for $16 \mathrm{~h}$ with $215 \mathrm{mM} \mathrm{NaOH}$. In addition, rProtein A Sepharose was significantly more affected by the $\mathrm{NaOH}$, with a $\mathrm{COG}$ shift of $0.6 \pm 0.1 \mathrm{~cm}^{-1}$, than MabSelect resin, with a COG shift of $0.4 \pm$ $0.1 \mathrm{~cm}^{-1}$. For rProtein A Sepharose, $>400 \mathrm{mM}$ trehalose significantly reduced, but did not abolish, the $\mathrm{NaOH}$-induced shift. The trehalose may help to reduce the denaturing effect of $\mathrm{NaOH}$ by stabilising the Protein A ligand. Higher trehalose concentration may have a greater stabilisation effect, but buffer dilution and the $1.8 \mathrm{M}$ solubility limit the maximum concentration in solution during CIP [63]. However, addition of up to $700 \mathrm{mM}$ trehalose to the buffer did not cause any significant reduction of the amide II COG for MabSelect SuRe resin. These results may be due to the greater resistance of MabSelect SuRe to $\mathrm{NaOH}$. Alternatively, the larger errors resulting from the lower ligand density could have hidden the effect of trehalose. Using our experimental approach, many more conditions could be rapidly screened to directly evaluate the effect of the buffer alkalinity on the Protein A ligand's conformation either after CIP or in situ.

\section{Conclusions}

This work represents the first studies of protein ligand denaturation on agarose stationary phase by infrared spectroscopy. By probing only a thin layer near the resin surface, ATR-FTIR spectroscopy proved particularly well suited to study Protein A ligand immobilised on soft agarose matrix. ATR-FTIR spectroscopic imaging confirmed that a homogenous contact between the IRE and resin beads can be obtained by applying a well-controlled load. If the load could be controlled separately in multiple wells, spectroscopic imaging could also allow high-throughput studies of multiple conditions simultaneously [45, 31]. ATR-FTIR spectroscopy allowed measurement of both ligand conformation and the amount of adsorbed protein on the beads following cleaning-in-place (CIP). Because proteolytic degradation of the Protein A ligand reduces IgG binding, the local protein concentration correlates with the static binding capacity assay results. Under milder conditions, cooperative changes in the tertiary and secondary structure conformations can still affect ligand functionality [24]. Our approach revealed that $\mathrm{NaOH}$ induced a conformational change in the protein ligand and that the binding capacity correlates with infrared absorption frequencies.

At $\mathrm{NaOH}$ concentrations typically used for CIP, between 100 and $1000 \mathrm{mM}$, ATR-FTIR spectroscopy detected significant conformational changes, but no significant ligand loss. We concluded that binding capacity decay following a typical CIP protocol result from Protein A ligand denaturation due to unfolding rather than proteolysis.

The results also revealed that high concentration trehalose solutions can reduce the effect of $\mathrm{NaOH}$ on Protein A conformation for rProtein A Sepharose. Since trehalose is massproduced for sweetening applications [63], adding the disaccharide to CIP protocol represents an economical solution to extending immunoaffinity resin lifespan.

Unlike UV spectroscopy [16], nearly every organic molecule absorbs mid-infrared light, resulting in characteristic spectra with multiple distinct peaks $[30,32]$ allowing identification of host cell proteins, aggregated mAbs, nucleic acids, fatty acids, phospholipids, cholesterol or any other contaminants building up during purification. Ultimately, ATR spectroscopic sensors could be embedded to column casings to monitor the build-up of contaminants as well as Protein A ligand degradation in situ. By providing direct insights into the state of the protein A ligand, stationary phase sensing could thus deliver important improvements to the downstream purification process.

Acknowledgements The authors wish to thank the BBRSC and the Bioprocessing Research Industry Club (BRIC) for funding this research (BB/K0111030/1).

Conflict of interest The authors declare that they have no conflicts of interest.

Open Access This article is distributed under the terms of the Creative Commons Attribution 4.0 International License (http:// creativecommons.org/licenses/by/4.0/), which permits unrestricted use, distribution, and reproduction in any medium, provided you give appropriate credit to the original author(s) and the source, provide a link to the Creative Commons license, and indicate if changes were made. 


\section{References}

1. (2012) Global biopharmaceutical market report \& forecast 20122017. International Market Analysis Research and Consulting Group. OCLC Number: 842158980

2. Rader RA (2013) FDA biopharmaceutical product approvals and trends in 2012. BioProcess Int BioProcess Int 11(3):18-27

3. Philippidis A (2012) Large molecules continue to gain favor. Genet Eng Biotechnol 32(10):10-11

4. (2015) Going large. The Economist. The Economist Newspaper Limited, January 3

5. Li R, Dowd V, Stewart DJ, Burton SJ, Lowe CR (1998) Design, synthesis, and application of a protein A mimetic. Nat Biotechnol 16(2):190-195

6. Reichert JM (2013) Which are the antibodies to watch in 2013? MAbs 5(1):1-4. doi:10.4161/mabs.22976

7. Malik NN (2009) Controlling the cost of innovative cancer therapeutics. Nat Rev Clin Oncol 6(9):550-552

8. Kelley B (2007) Very large scale monoclonal antibody purification: the case for conventional unit operations. Biotechnol Prog 23(5): 995-1008. doi:10.1021/bp070117s

9. Steinbrook R (2008) Saying no isn't NICE-the travails of Britain's National Institute for Health and Clinical Excellence. N Engl J Med 359(19):1977-1981

10. Goding JW (1978) Use of staphylococcal protein A as an immunological reagent. J Immunol Methods 20:241-253. doi:10.1016/ 0022-1759(78)90259-4

11. Baneyx F, Mujacic M (2004) Recombinant protein folding and misfolding in Escherichia coli. Nat Biotechnol 22(11):13991408. doi:10.1038/nbt1029

12. Johansson HJ, Ljunglöf A, Palmgren R (2011) Affinity chromatography matrix. Google Patents

13. Hogwood CE, Bracewell DG, Smales CM (2013) Host cell protein dynamics in recombinant $\mathrm{CHO}$ cells: impacts from harvest to purification and beyond. Bioengineered 4(5):288-291. doi:10.4161/ bioe. 23382

14. Pharmacia Biotech AB (1993) Affinity chromatography: principles and methods. Rahms, Lund

15. Guiochon G, Beaver LA (2011) Separation science is the key to successful biopharmaceuticals. J Chromatogr A 1218(49):8836-8858

16. Jiang CP, Liu J, Rubacha M, Shukla AA (2009) A mechanistic study of Protein A chromatography resin lifetime. J Chromatogr A 1216(31):5849-5855. doi:10.1016/j.chroma.2009.06.013

17. Gronberg A, Eriksson M, Ersoy M, Johansson HJ (2011) A tool for increasing the lifetime of chromatography resins. MAbs 3(2):192202. doi:10.4161/mabs.3.2.14874

18. Hahn R, Shimahara K, Steindl F, Jungbauer A (2006) Comparison of protein A affinity sorbents III. Life time study. J Chromatogr A 1102(1-2):224-231. doi:10.1016/j.chroma.2005.10.083

19. Hale G, Drumm A, Harrison P, Phillips J (1994) Repeated cleaning of protein A affinity column with sodium hydroxide. J Immunol Methods 171(1):15-21. doi:10.1016/0022-1759(94)90223-2

20. Burgoyne RF, Priest MC, Roche KL, Vella G (1993) Systematic development and validation of sanitization protocols for a chromatographic system designed for biotherapeutics purification. $\mathrm{J}$ Pharm Biomed 11(11):1317-1325

21. Girot P, Moroux Y, Duteil XP, Nguyen C, Boschetti E (1990) Composite affinity sorbents and their cleaning in place. J Chromatogr A 510:213-223

22. Asplund M, Ramberg M, Johansson B-L (2000) Development of a cleaning in place protocol and repetitive application of Escherichia coli homogenate on STREAMLINE ${ }^{\mathrm{TM}} \mathrm{Q}$ XL. Process Biochem 35(10):1111-1118

23. Hober S, Nord K, Linhult M (2007) Protein A chromatography for antibody purification. J Chromatogr B 848(1):40-47
24. Cheung MS, Finke JM, Callahan B, Onuchic JN (2003) Exploring the interplay between topology and secondary structural formation in the protein folding problem. J Phys Chem B 107(40):1119311200

25. Clarke S (1987) Propensity for spontaneous succinimide formation from aspartyl and asparaginyl residues in cellular proteins. Int $\mathrm{J}$ Pept Protein Res 30(6):808-821

26. Hahn R, Schlegel R, Jungbauer A (2003) Comparison of protein A affinity sorbents. J Chromatogr B 790(1-2):35-51. doi:10.1016/ s1570-0232(03)00092-8

27. Edelmann A, Lendl B (2002) Toward the optical tongue: flow-through sensing of tannin-protein interactions based on FTIR spectroscopy. J Am Chem Soc 124(49):14741-14747. doi:10.1021/ja026309v

28. deJongh HHJ, Goormaghtigh E, Ruysschaert JM (1996) The different molar absorptivities of the secondary structure types in the amide I region: an attenuated total reflection infrared study on globular proteins. Anal Biochem 242(1):95-103

29. Oberg KA, Ruysschaert JM, Goormaghtigh E (2004) The optimization of protein secondary structure determination with infrared and circular dichroism spectra. Eur J Biochem 271(14):29372948. doi:10.1111/j.1432-1033.2004.04220.x

30. Barth A (2000) The infrared absorption of amino acid side chains. Prog Biophys Mol Biol 74:141-173

31. Boulet-Audet M, Byrne B, Kazarian SG (2014) High-throughput thermal stability analysis of a monoclonal antibody by attenuated total reflection FT-IR spectroscopic imaging. Anal Chem 86(19): 9786-9793. doi:10.1021/ac502529q

32. Kazarian SG, Chan KLA (2013) ATR-FTIR spectroscopic imaging: recent advances and applications to biological systems. Analyst 138(7):1940-1951. doi:10.1039/c3an36865c

33. Glassford SE, Byrne B, Kazarian SG (2013) Recent applications of ATR FTIR spectroscopy and imaging to proteins. Biochim Biophys Acta-Proteins Proteomics 1834(12):2849-2858. doi:10.1016/j. bbapap.2013.07.015

34. Burgi T, Baiker A (2002) In situ infrared spectroscopy of catalytic solid-liquid interfaces using phase-sensitive detection: enantioselective hydrogenation of a pyrone over $\mathrm{Pd} / \mathrm{TiO}_{2}$. J Phys Chem B 106(41):10649-10658. doi:10.1021/jp0255987

35. Ninness BJ, Bousfield DW, Tripp CP (2001) In situ infrared technique for studying adsorption onto particulate silica surfaces from aqueous solutions. Appl Spectrosc 55(6):655-662. doi:10.1366/ 0003702011952505

36. Giacomelli CE, Bremer MG, Norde W (1999) ATR-FTIR study of IgG adsorbed on different silica surfaces. J Colloid Interface Sci 220(1):13-23

37. Wang Z, Larsson ML, Grahn M, Holmgren A, Hedlund J (2004) Zeolite coated ATR crystals for new applications in FTIR-ATR spectroscopy. Chem Commun 24:2888-2889. doi:10.1039/ b410314a

38. Everall NJ, Priestnall IM, Clarke F, Jayes L, Poulter G, Coombs D, George MW (2009) Preliminary investigations into macroscopic attenuated total reflection-Fourier transform infrared imaging of intact spherical domains: spatial resolution and image distortion. Appl Spectrosc 63(3):313-320

39. Müller TK, Cao P, Ewert S, Wohlgemuth J, Liu H, Willett TC, Theodosiou E, Thomas OR, Franzreb M (2013) Integrated system for temperature-controlled fast protein liquid chromatography comprising improved copolymer modified beaded agarose adsorbents and a travelling cooling zone reactor arrangement. J Chromatogr A 1285:97-109

40. Chan KLA, Tay FH, Poulter G, Kazarian SG (2008) Chemical imaging with variable angles of incidence using a diamond attenuated total reflection accessory. Appl Spectrosc 62(10):1102-1107

41. Harrick NJ (1965) Electric field strengths at totally reflecting interfaces. J Opt Soc Am 55(7):851-856 
42. Dousseau F, Therrien M, Pézolet M (1989) On the spectral subtraction of water from the FT-IR spectra of aqueous solutions of proteins. Appl Spectrosc 43(3):538-542

43. Harrick NJ (1967) Internal reflection spectroscopy. John Wiley \& Sons, New York

44. Keener RN, Maneval JE, Fernandez EJ (2004) Toward a robust model of packing and scale-up for chromatographic beds. 1 . Mechanical compression. Biotechnol Prog 20(4):1146-1158. doi: 10.1021/bp034279+

45. Kazarian SG (2007) Enhancing high-throughput technology and microfluidics with FTIR spectroscopic imaging. Anal Bioanal Chem 388(3):529-532. doi:10.1007/s00216-0071193-3

46. Sekkal M, Huvenne JP, Legrand P, Sombret B, Mollet JC, Mouradigivernaud A, Verdus MC (1993) Direct structural identification of polysaccharides from red algae by FTIR microspectroscopy. Mikrochim Acta 112(1-4):1-10. doi:10. 1007/bf01243315

47. Barsberg S (2010) Prediction of vibrational spectra of polysaccharides-simulated IR spectrum of cellulose based on density functional theory (DFT). J Phys Chem B 114(36):1170311708. doi:10.1021/jp104213z

48. Max JJ, Chapados C (2009) Isotope effects in liquid water by infrared spectroscopy. III. $\mathrm{H}(2) \mathrm{O}$ and $\mathrm{D}(2) \mathrm{O}$ spectra from 6000 to $0 \mathrm{~cm}(-1)$. J Chem Phys 131(18):184505. doi:10.1063/1. 3258646

49. Graille M, Stura EA, Corper AL, Sutton BJ, Taussig MJ, Charbonnier JB, Silverman GJ (2000) Crystal structure of a Staphylococcus aureus protein A domain complexed with the Fab fragment of a human IgM antibody: structural basis for recognition of B-cell receptors and superantigen activity. Proc Natl Acad Sci U S A 97(10):5399-5404. doi:10.1073/pnas.97.10.5399

50. Sato AK, Sexton DJ, Morganelli LA, Cohen EH, Wu QL, Conley GP, Streltsova Z, Lee SW, Devlin M, DeOliveira DB, Enright J, Kent RB, Wescott CR, Ransohoff TC, Ley AC, Ladner RC (2002) Development of mammalian serum albumin affinity purification media by peptide phage display. Biotechnol Prog 18(2):182-192. doi:10.1021/bp010181o

51. Porter D, Vollrath F (2008) The role of kinetics of water and amide bonding in protein stability. Soft Matter 4(2):328-336. doi:10.1039/ b713972a
52. Boulet-Audet M, Terry AE, Vollrath F, Holland C (2013) Silk protein aggregation kinetics revealed by Rheo-IR. Acta Biomater 10(2):776-784. doi:10.1016/j.actbio.2013.10.032

53. Goormaghtigh E, Cabiaux V, Ruysschaert J-M (1994) Determination of soluble and membrane protein structure by Fourier transform spectroscopy. II. Experimental aspects, sidechain structure and H/D exchange. In: Hilderson HJ, Ralston GB (eds) Physico-chemical methods in the study of biomembranes, vol 23. Plenum Press, New York, pp 363-403

54. Goormaghtigh E, Ruysschaert JM, Raussens V (2006) Evaluation of the information content in infrared spectra for protein secondary structure determination. Biophys J 90(8):2946-2957. doi:10.1529/ biophysj.105.072017

55. Saad P, Flach CR, Walters RM, Mendelsohn R (2012) Infrared spectroscopic studies of sodium dodecyl sulphate permeation and interaction with stratum corneum lipids in skin. Int J Cosmet Sci 34(1):36-43. doi:10.1111/j.1468-2494.2011.00678.x

56. Carbonell RG, Menegatti S, Naik AD (2013) Alkaline-stable chromatographic resins. Google Patents

57. Dipaola G, Belleau B (1977) Polyol-water interactions - apparent molal heat-capacities and volumes of aqueous polyol solutions. Can J Chem 55(22):3825-3830. doi:10.1139/v77-540

58. Zou Q, Bennion BJ, Daggett V, Murphy KP (2002) The molecular mechanism of stabilization of proteins by TMAO and its ability to counteract the effects of urea. J Am Chem Soc 124(7):1192-1202. doi:10.1021/ja004206b

59. Vogt G, Woell S, Argos P (1997) Protein thermal stability, hydrogen bonds, and ion pairs. J Mol Biol 269(4):631-643. doi:10.1006/ jmbi.1997.1042

60. Back JF, Oakenfull D, Smith MB (1979) Increased thermal-stability of proteins in the presence of sugars and polyols. Biochemistry 18(23):5191-5196. doi:10.1021/bi00590a025

61. Vollrath F, Hawkins N, Porter D, Holland C, Boulet-Audet M (2014) Differential scanning fluorimetry provides high throughput data on silk protein transitions. Sci Rep 4:5625. doi:10.1038/ srep05625

62. Jain NK, Roy I (2009) Effect of trehalose on protein structure. Protein Sci 18(1):24-36. doi:10.1002/pro.3

63. Higashiyama T (2002) Novel functions and applications of trehalose. Pure Appl Chem 74(7):1263-1269. doi:10.1351/ pac200274071263 